\title{
Minor pressure losses for different connections of PP-R and PEX/AI/PEX installation pipes
}

\author{
Kinga Ligaj ${ }^{1}$, Marcin K. Widomski ${ }^{1, *}$, and Anna Musz-Pomorska ${ }^{1}$ \\ ${ }^{1}$ Faculty of Environmental Engineering, Lublin University of Technology, ul. Nadbystrzycka 40B, \\ 20-618 Lublin, Poland
}

\begin{abstract}
This paper presents results of laboratory and numerical research concerning determination of water flow resistance through three types of two-way connection of polymer installation pipes: PP-R 20x3.4 $\mathrm{mm}$ and $\mathrm{PEX} / \mathrm{Al} / \mathrm{PEX} 16 \times 2.0 \mathrm{~mm}$. The following fittings were applied: the direct connection, pipe union and coupler, allowing to test six measurement variants. The laboratory measurements of pressure loss for the tested pipes connections were performed for variable Reynolds number, from approx. 5000 to 50000. The numerical modeling allowing to assess the distributions of velocity of flow and turbulence intensity were performed using FLUENT, Ansys Inc. modelling software. The relations between determined values of minor pressure loss and coefficients of local pressure losses and type of pipes connection, direction of flow as well as the value of Reynolds number were observed. The applied nonparametric statistics, combined with multi comparison, showed that in most cases of analyzed connections, besides the pipe union, the observed differences in pressure losses for various directions of flows are statistically significant for $\mathrm{p}=0.05$.
\end{abstract}

\section{Introduction}

The proper calculations of losses pressure losses in modern plastic pipes, including polyethylene (PE), cross-linked polyethylene (PEX), polypropylene (PP) and polyvinyl chloride (PVC) pipelines, which are nowadays very popular in various domestic installations, for which minor pressure losses may reach even the significant level of $40-60 \%$ of total pressure drop, is the important and rather difficult issue [1-4]. The modern pipelines may be connected in various combinations and in different manners, using several possible fittings, which may not fit to the values of coefficients of minor pressure losses presented in the former PN-M-34034:1976 [5], developed for different materials and fittings. Thus, the final calculated values of minor pressure drop were often reported as different than the real, measured values [3,6-10]. Moreover, the possible connections (such as pipe unions and couplers) may be located very close to the other elements installed on the plastic pipelines, which may additionally influence the possible pressure drop [11]. Finally, the assumed popular methodology of minor pressure drop calculations does not include the possible effect of Reynolds number [12, 13].

* Corresponding author: M.Widomski@pollub.pl 
Taking into account that values of minor pressure loss coefficients presented in PN-M-34034:1976 [5] for direct connections of pipes as well as for pipe union and coupler are in the range between $0.25-0.5$, the determination of real coefficients of minor pressure losses for selected connections of different pipelines is required.

This paper presents results of laboratory measurements and numerical studies of pressure loss during water flow through three types of two-way connection of polymer installation pipes: PP-R 20x3.4 mm and PEX/Al/PEX 16x2.0 mm. Three different possible connections of the tested pipelines were tested: the direct connection, pipe union and coupler.

\section{Materials and methods}

The performed research covered laboratory and numerical studies of water flow through three types of bidirectional connections of two popular plastic domestic installation pipes, PP-R 20x3.4 mm PN 20, according to PN-EN ISO 15874-2:2005 [14] and PEX/Al/PEX $16 \times 2.0 \mathrm{~mm}$ according to DIN 4726 [15]. The following fittings were applied: the direct connection, pipe union and coupler.

The laboratory measurements of minor pressure losses on tested connections were performed on installation presented in Fig. 1. The applied range of water volumetric flow rate was in range approx. $100-1500 \mathrm{dm}^{3} / \mathrm{h}$, reflected by the dimensionless Reynolds number between approx. 5000 and 50000. Measurements were conducted for two directions of flow and three selected connections of pipes, thus six variants of research were developed.

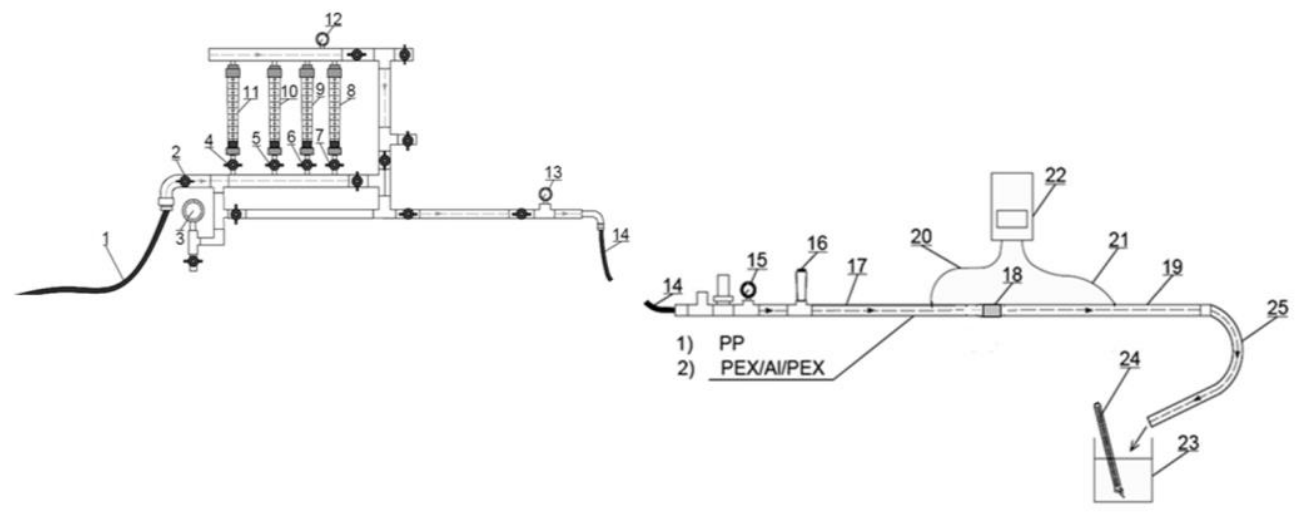

Fig. 1. Scheme of laboratory installation: 1- water supply pipe, 2, 4, 5, 6, 7-valves, 3, 12, 13, 15 - manometers, $8,9,10,11$ - rotameters, 14 - elastic water pipe, 16 - vent valve, 17, 19 PP-R and PEX/Al/PEX pipes, 18 - studied fitting, 20, 21 - pressure impulse pipes, 22 - electronic differential manometer, 23 - water reservoir, 24 - thermometer.

The performed experiments were based on measurements of pressure difference by electronic laboratory differential manometer by Lutron Electronic, Taiwan with $2 \%$ accuracy, while volumetric flow rate of water was determined by set of rotameters produced by Meister Strömungstechnik, Germany. Location of points of pressure measurements met requirements of PN-EN 1267:2012 [16]. The pressure sampling point before the connection was established at distance $>10 \mathrm{~d}$, while the point after the tested local loss was located at distance $>60 \mathrm{~d}$.

All laboratory measurements were repeated three times for each tested connection of pipes and applied volumetric flow rate of water. The laboratory installation was supplied 
with tap water with constant pressure obtained due to application of elevated water reservoir.

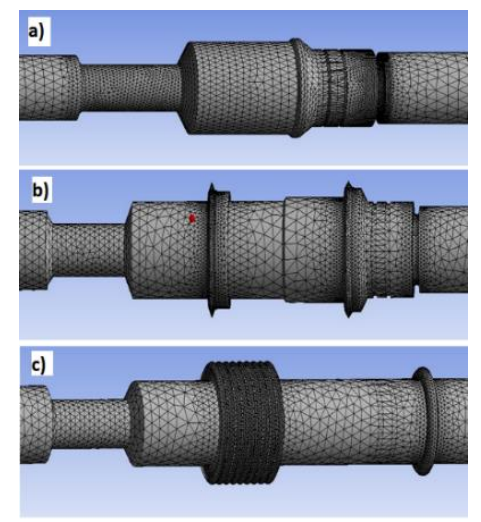

Fig. 2. Developed FEM models of tested connections: a) direct connection, b) pipe union, c) coupler.

Numerical modeling of water flow through tested pipes connections for two tested piping materials was performed in Fluent, ANSYS Inc. computing software. Three different 3D models in 1:1 scale, reflecting the real dimensions and shapes of waterbody for tested connections of pipes were developed. The variable direction of flow was obtained due to the assigned boundary conditions. The developed models consisted of the following numbers of nodes and finite elements: 47637 and 222010 for direct connection, 44016 and 203868 for pipe union and 48683 and 221004 for coupler, respectively. The developed models are presented in Fig. 2. Our calculations of viscous liquid flow were based on the standard two-equation k-epsilon turbulence model [17].

The required input data for numerical modeling covered characteristics of materials and boundary conditions. The assumed characteristics of water were directly based on measurements performed in laboratory and covered temperature $\left(16.5-21.5^{\circ} \mathrm{C}\right)$, dynamic viscosity $(0.00094-0.00107 \mathrm{~kg} /(\mathrm{m} \cdot \mathrm{s}))$ and density $\left(997.45-998.82 \mathrm{~kg} / \mathrm{m}^{3}\right)$. The inlet velocity boundary condition, covering velocity of flow, gauge pressure, hydraulic radius and turbulence intensity, was assumed at the inlet surface of the developed models. The initial percentage turbulence intensity $I$ was calculated for each of the computational variants according to the following formula [11]:

$$
I=0.16 \cdot R e^{-\frac{1}{8}}
$$

The wall boundary condition was assumed in Fluent as pipe material's roughness equal $k=7 \cdot 10^{-6} \mathrm{~m}$.

The resultant values of coefficient of minor losses for the tested pipe connections were calculated according to the transformed Bernoulli's equation:

$$
\zeta=\frac{2 g \cdot\left(\Delta h-\lambda_{1} \cdot \frac{l_{1} \cdot v_{1}^{2}}{d_{1} \cdot 2 g}-\lambda_{2} \cdot \frac{l_{2} \cdot v_{2}^{2}}{d_{2} \cdot 2 g}-\frac{v_{2}^{2}-v_{1}^{2}}{2 g}\right)}{v_{2}^{2}}
$$

where: $\zeta$ - coefficient of minor (local) losses [-], $g$ - gravity $\left[\mathrm{m} / \mathrm{s}^{2}\right], \Delta h-$ total pressure loss read from the differential manometer $\left[\mathrm{mH}_{2} \mathrm{O}\right], v_{i}-$ mean velocity of flow through pipeline before and after the fitting $[\mathrm{m} / \mathrm{s}], \lambda$ - coefficient of friction losses $[-], l_{1}, l_{2}-$ lengths of pipelines before and after the connection, measured to locations of pressure impulse pipes $[\mathrm{m}], d_{1}, d_{2}$ - diameters of pipes before and after the connection [m]. 
The required values of $\lambda$ coefficient of friction pressure losses were calculated according to the popular Colebrook-White's formula:

$$
\frac{1}{\sqrt{\lambda}}=-2 \log \left(\frac{2.51}{R e \sqrt{\lambda}}+\frac{k}{3.71 d}\right)
$$

where: $R e$ - dimensionless Reynolds number, $k$ - roughness of pipe material [mm].

The obtained results of laboratory research were statistically analyzed to assess the statistical significance of the observed differences between pressure losses and coefficients of minor pressure loss for tested connections and variable direction of flow. The Shapiro-Wilk test of normality and Wilcoxon signed-rank test as well as non-parametric Kruskal-Wallis' one-way analysis of variance were applied to our studies. Results of numerical calculations were validated by $\mathrm{R}^{2}$, the root mean square error (RMSE), ratio of the root mean square error to the standard deviation of measured data (RSR) and NashSutcliffe coefficient of model efficiency (NSE).

\section{Results and discussion}

The values of local pressure drop and coefficients of minor pressure loss for all tested connections of pipe, variable Reynolds number and two directions of flow $\mathrm{PP}-\mathrm{PEX} / \mathrm{Al} / \mathrm{PEX}$ and $\mathrm{PEX} / \mathrm{Al} / \mathrm{PEX}$ - PP, respectively, determined during laboratory studies, are presented in Fig. 3.
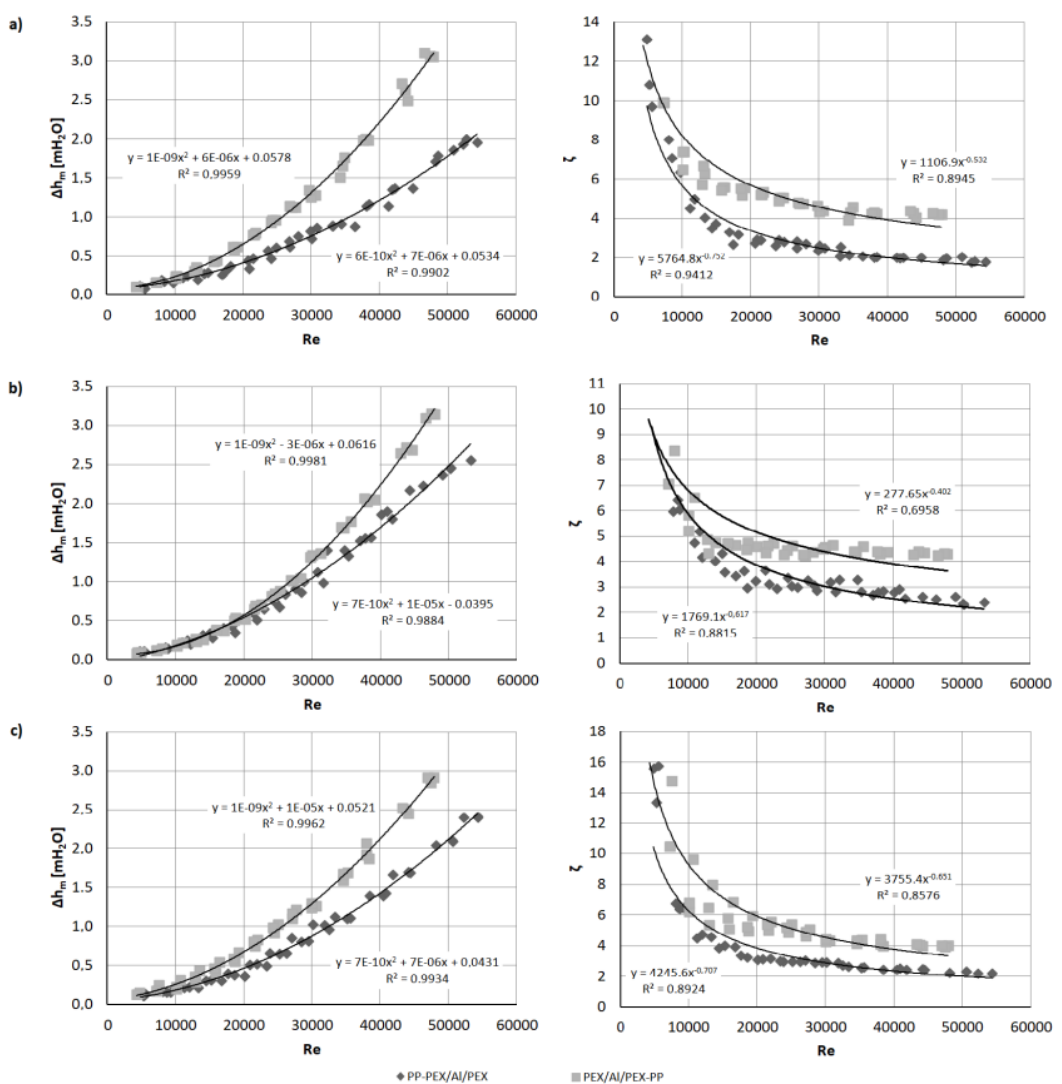

Fig. 3. Laboratory measurements of local pressure losses and coefficients of minor pressure loss for studied pipe connections. 
It is visible that all tested connections for different directions of flow generated various values of minor pressure drop and coefficients of minor pressure loss. Moreover, it should be underlined that in all the tested cases, for the three studied connections, the greater resistance of flow for the same Reynolds number was generated for connection of pipelines in direction PEX/Al/PEX - PP. Additionally, the dependence of minor loss coefficient to Reynolds number was also observed. The obtained results were summarized in Tab. 1.

Table 1. Range of variability of determined Re number, confidents of minor pressure loss and local pressure losses for tested connections.

\begin{tabular}{|c|c|c|c|c|c|c|c|c|}
\hline \multirow{2}{*}{$\begin{array}{c}\text { Type of } \\
\text { connection }\end{array}$} & \multicolumn{4}{|c|}{ PP - PEX/AI/PEX } & \multicolumn{4}{|c|}{ PEX/Al/PEX - PP } \\
\hline & Re range & $\zeta$ range & $\begin{array}{c}\zeta \\
\text { mean }\end{array}$ & $\begin{array}{l}\Delta h_{m}[-] \\
\text { range }\end{array}$ & $R e$ range & $\zeta$ range & $\begin{array}{c}\zeta \\
\text { mean }\end{array}$ & $\begin{array}{c}\Delta h_{m}[-] \\
\text { range }\end{array}$ \\
\hline Direct & $\begin{array}{l}4881- \\
54303\end{array}$ & $\begin{array}{l}1.77- \\
13.16 \\
\end{array}$ & 3.57 & $\begin{array}{c}0.08- \\
2.00 \\
\end{array}$ & $\begin{array}{l}4352- \\
47942\end{array}$ & $\begin{array}{l}3.91- \\
16.79 \\
\end{array}$ & 6.24 & $\begin{array}{c}0.10- \\
3.10\end{array}$ \\
\hline Pipe union & $\begin{array}{c}4741- \\
53248\end{array}$ & $\begin{array}{l}2.31- \\
13.41 \\
\end{array}$ & 4.1 & $\begin{array}{c}0.10- \\
2.56\end{array}$ & $\begin{array}{l}2470- \\
27942\end{array}$ & $\begin{array}{l}4.23- \\
15.63 \\
\end{array}$ & 5.51 & $\begin{array}{c}0.07- \\
3.16 \\
\end{array}$ \\
\hline Coupler & $\begin{array}{l}4881- \\
54303\end{array}$ & $\begin{array}{c}2.20- \\
15.76\end{array}$ & 4.09 & $\begin{array}{c}0.11- \\
2.41\end{array}$ & $\begin{array}{l}4352- \\
47942\end{array}$ & $\begin{array}{l}3.91- \\
24.63\end{array}$ & 6.84 & $\begin{array}{c}0.12- \\
2.92\end{array}$ \\
\hline
\end{tabular}

The determined values of coefficients of minor pressure loss for all tested connections are clearly higher than values presented in former Polish national standard PN-76/M-34034:1976 [5], which suggested constant values of $\zeta$ for all discussed fittings from range $0.25-0.5$. Moreover, the obtained results of our laboratory tests are generally higher than most of values of minor pressure loss coefficients suggested by nowadays producers, which commonly are in range $0.5-4.5$ for direct connection, $0.6-0.7$ for pipe union and $0.1-0.73$ for coupler, respectively.

The performed statistical analyses showed that according to Shapiro-Wilk test of normality all the tested variables showed distributions different than normal. The Wilcoxon test applied for pairs of series of results obtained for the same connection but different direction of flow showed statistically significant differences between determined medians of coefficients of minor pressure loss. The Kruskal-Wallis ANOVA test supplemented by multiple comparisons applied to all six series of laboratory measurements showed that the observed differences in distribution functions were statistically significant. The obtained results of post-hoc test of multiple comparisons for values of coefficients of minor pressure losses determined in laboratory are presented in Tab. 2.

Table 2. Results of $p$ for post-hoc multiple comparisons test for obtained values of minor loss coefficients for tested fittings and two directions of flow.

\begin{tabular}{|c|c|c|c|c|c|c|}
\hline Type of connection & $\begin{array}{c}\text { Direct } \\
\text { PEX-PP }\end{array}$ & $\begin{array}{c}\text { Direct } \\
\text { PP-PEX }\end{array}$ & $\begin{array}{c}\text { Pipe union } \\
\text { PP-PEX }\end{array}$ & $\begin{array}{c}\text { Pipe } \\
\text { union } \\
\text { PEX-PP }\end{array}$ & $\begin{array}{c}\text { Coupler } \\
\text { PP-PEX }\end{array}$ & $\begin{array}{c}\text { Coupler } \\
\text { PEX-PP }\end{array}$ \\
\hline Direct PEX-PP & - & 0.00057 & 0.01419 & 1 & 0.00779 & 1 \\
\hline Direct PP-PEX & 0.00057 & - & 1 & 0.00493 & 1 & 0.00032 \\
\hline $\begin{array}{c}\text { Pipe union } \\
\text { PP-PEX }\end{array}$ & 0.01419 & 1 & - & 0.08202 & 1 & 0.00886 \\
\hline Pipe union PEX-PP & 1 & 0.00493 & 0.08202 & - & 0.0488 & 1 \\
\hline Coupler PP-PEX & 0.00779 & 1 & 1 & 0.0488 & - & 0.00477 \\
\hline Coupler PEX-PP & 1 & 0.00032 & 0.00886 & 1 & 0.00477 & - \\
\hline
\end{tabular}

The numerical simulation in the performed studies was generally used to determine the factors affecting generation of resistance of flow for the three tested fittings and two directions of flow. The above assessment was based on determined distributions of 
magnitude of flow velocity and turbulence intensity for each tested case. The exemplary graphs showing distribution of $v$ and $I$ for each tested case and selected volumetric flow rate are presented in Figs 4 and 5.

a)
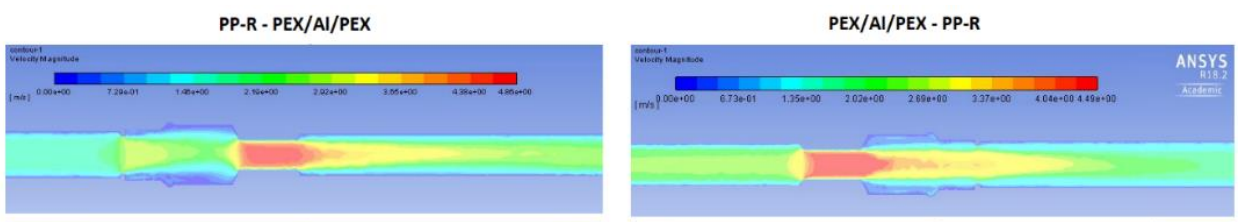

b)
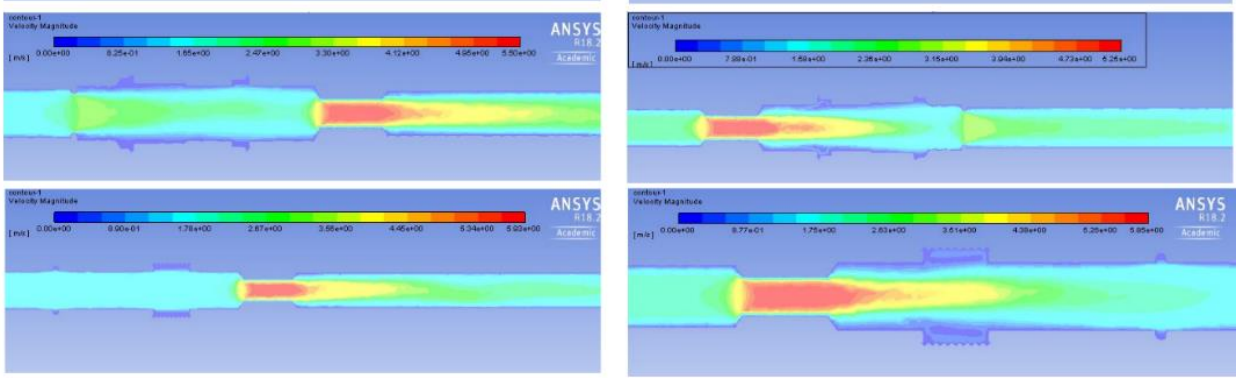

Fig. 4. Modelled distributions of velocity magnitude for selected flow rate $\left(800 \mathrm{dm}^{3} / \mathrm{hr}\right)$ : a) direct connection, b) pipe union, c) coupler.

a)
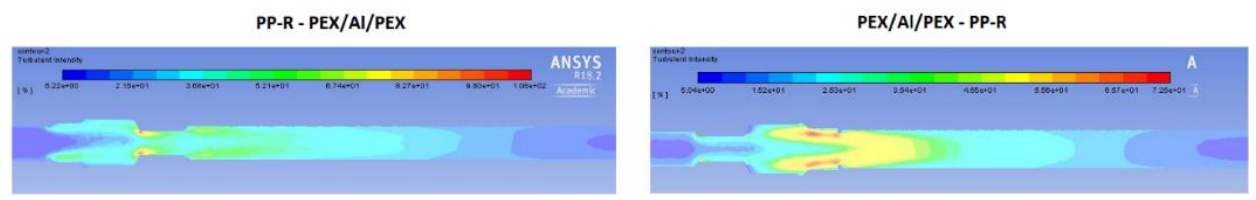

b)
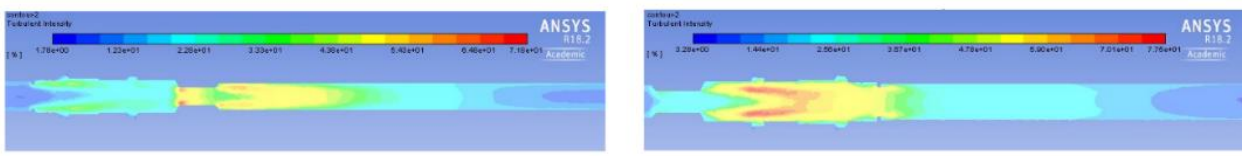

c)
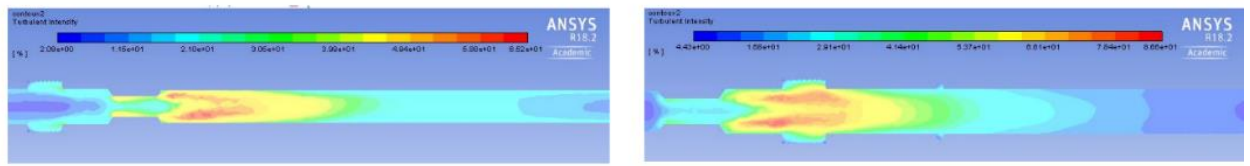

Fig. 5. Modelled distributions of turbulence intensity for selected flow rate $\left(800 \mathrm{dm}^{3} / \mathrm{hr}\right)$ : a) direct connection, b) pipe union, c) coupler.

The clear differences between distributions of flow velocity and turbulence intensity caused by different shape of waterbodies are visible. The highest local velocity of flow was detected for both direction of flow through the tested coupler. The highest local turbulence intensity in direction PP-PEX/Al/PEX was observed for the direct connection, while, in the opposite direction, PEX/Al/PEX-PP, the highest level of turbulence intensity was reached in waterbody of the coupler. Generally, connection of tested domestic installation pipes by all studied fittings resulted in significant increase in turbulence intensity, from approx. 5\% typical for undisturbed turbulent flow inside the pipeline to level of approx. $65-108 \%$. Similarly, installation of the tested fittings resulted in increase in the local velocity of flow from approx. $1.7 \mathrm{~m} / \mathrm{s}$ to the values close to $4.86-5.93 \mathrm{~m} / \mathrm{s}$.

The determined results of model validation covering $\mathrm{R}^{2}$, RMSE, RSR and NashSutcliffe coefficient of model efficiency presented in Tab. 3 showed the satisfactory performance of the developed model $[18,19]$. 
Table 3. Results of model validation for all tested fittings and flow directions.

\begin{tabular}{|c|l|c|c|c|c|}
\hline Type of connection & Direction of flow & $\mathbf{R}^{\mathbf{2}}$ & $\mathbf{R S M E}$ & $\mathbf{R S R}$ & $\mathbf{N S E}$ \\
\hline \multirow{3}{*}{ Dirtect } & PP-PEX/AL/PEX & 0.9967 & 0.086 & 0.135 & 0.982 \\
\cline { 2 - 6 } & PEX/AL/PEX-PP & 0.9983 & 0.383 & 0.425 & 0.819 \\
\hline \multirow{2}{*}{ Pipe union } & PP-PEX/AL/PEX & 0.9967 & 0.624 & 0.881 & 0.224 \\
\cline { 2 - 6 } & PEX/AL/PEX-PP & 0.9983 & 0.700 & 0.828 & 0.314 \\
\hline \multirow{2}{*}{ Coupler } & PP-PEX/AL/PEX & 0.9972 & 0.358 & 0.471 & 0.778 \\
\cline { 2 - 6 } & PEX/AL/PEX-PP & 0.9984 & 0.514 & 0.552 & 0.695 \\
\hline
\end{tabular}

\section{Conclusions}

The performed laboratory measurements of local pressure losses for three different connections of PP-R and PEX/Al/PEX domestic installation pipelines and two applied directions of flow showed that all tested fittings generated different local pressure drop, also in relation to the applied direction of flow. The greater resistance of flow, related to the shape of waterbody of each connection, leading to higher local pressure losses and expressed by higher values of coefficients of minor pressure losses were in all cases observed for direction of flow PEX/A1/PEX - PP-R. Additionally, in all of the tested cases (different connections and variable direction of flow) the determined values of minor pressure losses coefficients were greater than values suggested by the standards and technical guidelines. The performed numerical simulation of water flow through the tested fitting showed that the developed shape of waterbody for each of the tested connections and each applied Reynolds number significantly influenced the resultant pressure drop, due to different values and spatial distributions of flow velocity and turbulence intensity. In our opinion the presented problem should be carefully studied, because underestimated minor pressure losses inside various domestic installations may significantly decrease their functionality.

\section{References}

1. M. Annan, E. A. Gooda, A. E. J. 57, 4299-4305 (2018)

2. I. Cisowska, A. Kotowski, Fundations of Civil and Environ. Eng. 8, 37-57 (2006)

3. P. Grajper, J. Smołka, Gaz, Woda i Technika Sanitarna, 7-8 (2010)

4. K. Weinerowska-Bords, Instal 6, 42-49 (2014)

5. PN-M-34034 Pipelines - Rules for the calculation of pressure losses (1976)

6. T. Siwiec, D. Morawski, G. Karaban, Gaz, Woda i Technika Sanitarna 2 (2002)

7. I. Cisowska, A. Kotowski, Gaz, Woda i Technika Sanitarna 10 (2004)

8. K. Strzelecka, K. Jeżowiecka-Kabsch, Ochrona Środowiska 30, 2 (2008)

9. K. Strzelecka, K. Jeżowiecka-Kabsch, Ochrona Środowiska 32, 1 (2010)

10. M. K. Widomski, A. Musz, M. Iwanek, Gaz, Woda i Technika Sanitarna 9, 380-385 (2012)

11. Ansys. Inc., Ansys Fluent User's Guide. Release 19.0 (2018)

12. Y. Bae, Y. In Kim, Ann. Nucl. Energy 73, 33-38 (2014) 
13. N. Moallemi, J. R. Brinkerhoff, Comput. Fluids. 140, 209-221 (2016)

14. PN-EN ISO 15874-2 Plastic pipe systems for the installation of hot and cold water-Polypropylene (PP) - Part 2: Pipes (2005)

15. DIN 4726 Warm water surface heating systems and radiator connecting systems Plastics piping systems and multilayer piping systems (German National Standard, 2017)

16. PN-EN 1267 Industrial fittings - Testing the resistance of water flow (2012)

17. B. E. Launder, D. B. Spalding, J. Heat Mass Transfer 1, 2, 131-138 (1974)

18. D. N. Moriasi, J. G. Arnold, M. W. Van Liew, R. L. Bingner, R. D. Harmel, T. L. Veith, ASABE 50, 885-900 (2007)

19. G. Golmohammadi, S. Prasher, A. Madani, R. Rudra, Hydrology 1, 20-39 (2014) 